\title{
LA INEFICACIA DE LAS REGLAS DE EJECUCIÓN DE LAS SENTENCIAS ALIMENTARIAS PARA NIÑOS, NIÑAS Y ADOLESCENTES
}

\section{THE INEFFECTIVENESS OF THE RULES FOR THE EXECUTION OF FOOD SENTENCES FOR CHILDREN AND ADOLESCENTS}

\author{
Abner Príncipe Mena* \\ Investigador independiente \\ Lima-Perú \\ https: / / orcid.org/0000-0002-1621-4113 \\ abner077@gmail.com
}

\section{Resumen}

El presente artículo tiene por objeto desarrollar algunas reflexiones sobre el proceso de alimentos en la etapa de ejecución de sentencia; toda vez que, constituye la etapa procesal que mayores inconvenientes viene presentando en perjuicio de los justiciables pertenecientes a la infancia. Por ello, se resalta la importancia de contar con reglas y procedimientos sencillos e idóneos, así como una labor e interpretación tuitiva de la jurisdicción al momento de ejecutar la sentencia; a fin de garantizar en forma efectiva el derecho fundamental a la obtención de la pensión alimenticia.

Palabras clave: Pensión de alimentos; ejecución efectiva de la sentencia; liquidación de pensiones devengadas.

\section{Abstract}

The purpose of this article is to develop some reflections on the maintenance process at the sentencing stage; since it constitutes the procedural stage that has been presenting the greatest inconveniences to the detriment of the defendants belonging to children. For this reason, the importance of having simple and suitable rules and procedures as well as a protective work and interpretation of the jurisdiction at the time of executing the sentence is highlighted; in order to effectively guarantee the fundamental right to obtain alimony.

Keywords: Alimony; effective execution of the sentence; settlement of accrued pensions.

Juez de Paz Letrado Titular, actualmente Juez de Familia en la Corte Superior de Justicia de Lima Este. 


\section{INTRODUCCIÓN}

En el presente artículo se desarrollan algunas reflexiones sobre el proceso de alimentos como mecanismo institucional de protección del derecho a la pensión alimenticia de niños, niñas y adolescentes. Se parte sosteniendo que la pensión de alimentos constituye un auténtico derecho fundamental que exige del Estado el deber de establecer reglas y procedimientos rápidos y sencillos para el oportuno goce y satisfacción de los derechos alimentarios.

El enfoque principal consiste en la etapa de ejecución de sentencia, en la cual, desde nuestra opinión, se encontraría el principal problema del proceso de alimentos, tanto de nivel legislativo como jurisdiccional. Ello se debe a la ausencia de reglas claras e idóneas, así como a la incorrecta interpretación y aplicación que se le viene dando en la administración de justicia, situación que afecta el derecho a la tutela jurisdiccional efectiva y el derecho a obtener las pensiones alimenticias en forma oportuna.

Se observará que el verdadero calvario de los justiciables comienza luego de emitida la sentencia de alimentos que pretenden ejecutarla. La existencia de antinomias e incongruencias normativas obstaculizan el inicio la ejecución de la sentencia debido a que, por un lado, se habilita que aquella sea ejecutada, aunque haya apelación y, por otro, se exige que la sentencia tenga la calidad de firme. Cabe añadir la poca utilidad de la figura de la ejecución anticipada de sentencia que se forma en cuaderno separado, en los casos de renuencia del obligado al pago de las pensiones alimenticias.

De otro lado, se ingresa al análisis de cómo la interpretación de las disposiciones normativas efectuadas por jueces y juezas impiden la ejecución oportuna de la sentencia, al considerar que el juez no podría impulsar de oficio los actos de ejecución necesarios para la obtención de las pensiones alimenticias, concretamente los casos relativos a la remisión de las copias certificadas de la liquidación de las pensiones devengadas. También se verifica el rechazo de los pedidos de las partes para el inicio de la ejecución por errores que pueden ser subsanados de oficio por el órgano jurisdiccional; así como la exigencia de la notificación del requerimiento de pago de las pensiones devengadas que retarda mucho más en cumplimiento del pago.

Es importante conocer los problemas concretos que se vienen presentando en la etapa de ejecución de la sentencia de alimentos; en 
principio, porque poco se ha dicho y escrito sobre esta problemática, y porque es urgente que se verifiquen exhaustivamente las reglas de ejecución, así como la interpretación y aplicación que se le viene dando en los órganos jurisdiccionales. Asimismo, conocer tal problemática permitirá reflexionar sobre su regulación actual y sobre la necesidad de contar con instrumentos idóneos para la protección efectiva del derecho fundamental a la pensión alimenticia, según se apreciará en las líneas siguientes.

\section{LAPENSIÓNDEALIMENTOSCOMODERECHOFUNDAMENTAL}

Existe profuso desarrollo doctrinal y normativo sobre el derecho a la pensión de alimentos y el mecanismo institucional que establece el Estado para su protección: el proceso de alimentos. Sin embargo, poco se ha escrito respecto de la categoría de dicho derecho, pues si bien se dice que se trata de un derecho fundamental, no se han desarrollado las razones que justifican tal categoría; pese a que se trata de un tema de vital importancia, de cara a establecer cuál es el rol del Estado social y democrático de derecho en su protección efectiva.

No se pretende en este trabajo ingresar a un desarrollo exhaustivo del derecho a la pensión alimenticia; no obstante, ello, consideramos importante empezar precisando algunas razones por las que se debe considerar que se trata de un verdadero derecho fundamental.

Si revisamos la Constitución Política del Estado podríamos afirmar que, aparentemente, no se trataría de un derecho fundamental expresamente reconocido por la Constitución. Y es que el artículo 4 de la Norma Fundamental alude de manera genérica a la protección especial del niño y el artículo 6, segundo párrafo, establece como deberes de los padres alimentar, educar y dar seguridad a los hijos. Sin embargo, el hecho de que no se encuentre escrito o enumerado en el texto constitucional no quiere decir que el derecho a la pensión alimenticia no responda a un auténtico derecho fundamental plenamente reconocido.

Existen dos grandes grupos de derechos fundamentales, específicamente los derechos expresamente positivados (o escritos) y los derechos fundamentales no escritos, aquí generalmente considerados aquellos que no fueron objeto de previsión expresa en el derecho positivo constitucional o internacional. Los derechos fundamentales escritos son los que se encuentran en el catálogo de derechos fundamentales o en otra parte del texto constitucional (derechos con status constitucional material y formal) así como los derechos fundamentales contenidos en los tratados 
internacionales y que igualmente fueron expresamente positivados. (Sarlet, 2019 p. 114)

De este modo, si un derecho no está en la Constitución, pero sí en un tratado no sería uno de carácter innominado, sino un derecho expresamente reconocido (Sáenz 2009: 13 - 47), a la luz de lo prescrito por el artículo 55 de la Constitución, que establece que los tratados celebrados por el Estado y en vigor forman parte del derecho nacional. Serán derechos fundamentales reconocidos no solo los que se encuentran dentro del catálogo de la Constitución, sino los que también se encuentren expresamente reconocidos en los tratados internacionales ratificados por el Estado peruano.

La Convención sobre los Derechos del Niño, aprobada por el Perú mediante Resolución Legislativa N. ${ }^{\circ} 25278$, el 14 de agosto de 1990, vigente desde el 02 de setiembre del mismo año, establece en su artículo 27, numeral 1, que los Estados Partes reconocen el derecho de todo niño a un nivel de vida adecuado para su desarrollo físico, mental, espiritual, moral y social. El numeral 4 de dicha disposición prescribe que: Los Estados Partes tomarán todas las medidas para asegurar la pensión alimenticia por parte de los padres $u$ otras personas que tengan la responsabilidad financiera por el niño, tanto si viven en el Estado parte como si viven en el extranjero.

El derecho a la pensión alimenticia se encuentra reconocido expresamente en la Convención sobre los Derechos del Niño, al establecer el derecho de todo niño a un nivel de vida adecuado para su desarrollo físico, mental, espiritual, moral y social; y, a su vez, ordena que los Estados partes, como el Estado peruano, adopten todas las medidas para asegurar la pensión alimenticia del niño, niña o adolescente. Si la pensión de alimentos es un derecho reconocido explícitamente por la Convención sobre los Derechos del Niño, el reconocimiento explícito se extiende a todo nuestro ordenamiento jurídico interno; razón por la cual, la pensión de alimentos se constituye como un auténtico derecho fundamental reconocido expresamente en nuestro orden constitucional.

A través de la pensión de alimentos se concretiza el derecho a los alimentos, que no reduce únicamente a la alimentación (bienes comestibles) sino a todo lo necesario para garantizar un nivel de vida adecuado para el desarrollo físico, mental, espiritual y social del niño, niña o adolescente; de manera que, tal como lo sostiene el profesor Aguilar Llanos:

Los alimentos del latín alimentum, significa nutrir, y aun cuando la palabra alimentos es sinónimo de "comida", no debemos 
reducir el instituto solo al sustento, sino que el concepto es más amplio, extenso, pues comprende el sustento, la habitación (vivienda), vestido, asistencia médica y psicológica, y si el acreedor alimentario es menor de edad, también incluye la educación y el rubro recreo, como parte importante de la atención integral del niño y adolescente. (2016 p. 488)

La finalidad de la pensión alimenticia es que su beneficiario cuente con todo aquello que resulte necesario para garantizar de manera efectiva la satisfacción de sus necesidades propiamente humanas en sus dimensiones material, espiritual, individual y social ${ }^{3}$. Así lo ha reconocido el legislador en el artículo 92 del Código de los Niños y Adolescentes, al considerar a los alimentos como todo lo necesario para el sustento, habitación, vestido, educación, instrucción y capacidad para el trabajo, asistencia médica y psicológica y recreación del niño o del adolescente.

De esta forma, se hace indispensable que el Estado establezca garantías institucionales y procesales efectivas que permitan una plena y real satisfacción de la pensión alimenticia por sus titulares menores de edad. Lo contrario, la ausencia de mecanismos procesales efectivos para protegerlo, vaciaría de contenido y poco importaría su estatus constitucional. Los derechos fundamentales son valiosos en la medida en que cuentan con garantías procesales que permitan accionarlos no solo ante los tribunales, sino también ante la administración e incluso entre los particulares (Landa 2018: 496). Por ello, un Estado constitucional de derecho que se precie garante de derechos fundamentales debe contar con mecanismos y garantías procesales efectivas para que toda persona pueda hacer uso de ellas y lograr la protección de su derecho a la pensión alimenticia, en forma oportuna y sencilla.

El mecanismo para proteger el derecho alimentario es el proceso de alimentos, regulado por las disposiciones contenidas en el Subcapítulo 1, Capítulo II, Título III de la Sección Quinta del Código Procesal Civil. Las disposiciones normativas que regulan el proceso de alimentos para niños, niñas y adolescentes, se encuentran contenidas en Capítulo IV del Título I del Libro III, del Código de los Niños y Adolescente.

El cuerpo de la persona humana presenta una serie de exigencias y necesidades. La primera y fundamental es la de mantenerse con vida, para lo cual - por ejemplo - debe satisfacer necesidades de alimentación. Una segunda, también fundamental, es que la existencia no puede ser cualquier existencia. Debe ser una tal que permita a la persona humana operar sus distintas facultades propiamente humanas. Respecto al ámbito espiritual, se reconoce en la persona humana, una fuerza que anima su cuerpo y que es capaz de determinarlo y de dirigirlo en su actuación. En ese contexto aparece el alma humana como una realidad espiritual dotada de entendimiento y de voluntad libres, por lo que es independiente del cuerpo o materia misma (Castillo Córdova, Luis (2007).Los Derechos Constitucionales. Elementos para una teoría general. Lima: Palestra Editores, p. 31-33) 
Siendo el proceso de alimentos el mecanismo institucional que establecenuestroordenamientojurídicoparagarantizarelderechoalimentario, dicho proceso debe ser uno que resulte sencillo, rápido y efectivo para el verdadero cumplimiento y satisfacción de las pretensiones alimentarias. De esta forma, las disposiciones legales sobre la materia y su aplicación por los jueces y juezas en los procesos con pretensiones alimentarias deben ser idóneos no solo para facilitar el acceso a la administración de justicia, tener un debido proceso y obtener la sentencia que resuelve el caso; sino también, y sobre todo, se debe contar con instrumentos procesales claros e idóneos para ejecutar la sentencia judicial que fija el monto por concepto de pensión de alimentos.

Frente a la falta de reglas idóneas o cuando las que establece el ordenamiento procesal resultan un obstáculo para garantizar la ejecución efectiva de la sentencia, el juez debe contar con poderes jurisdiccionales suficientes para garantizar la ejecución oportuna de la sentencia y la satisfacción del derecho a la pensión alimenticia. Una verdadera protección de este derecho fundamental exige que el juez esté munido de poder jurisdiccional suficiente para la tutela efectiva de los derechos; de manera que, se debe admitir que el juez puede suprimir la omisión o la insuficiencia de la protección normativa procesal. (Marinoni, 2016 p. 29)

\section{EL ROL DEL JUEZ EN EL PROCESO: EN EL TRÁNSITO DEL ESTADO LEGAL DE DERECHO AL ESTADO CONSTITUCIONAL DE DERECHO}

En el Estado legal de derecho toda actuación del aparato estatal se reducía a la supremacía de la ley, de manera que, era la aplicación de la ley lo que determinada la protección de los derechos y libertades de las personas. En el Estado legicentrista:

“(...) la ley es algo más -y distinto- que un instrumento técnico para garantizar los derechos y libertades que ya se poseen. La ley es más bien un valor en sí y no un mero instrumento, porque solo gracias a su autoridad se hacen posible los derechos y las libertades de todos: con su ausencia, faltando un legislador firme y autorizado se caería en el detestado pasado de la sociedad de los privilegios del Antiguo Régimen". (Fioravanti, 2009 p. 56).

Los derechos fundamentales existían y debían protegerse en la medida que previamente lo reconocía la ley, máxima fuente del derecho, y a la vez, como consecuencia también modo principal y privilegiado de garantía 
de derechos; porque solo en la dimensión de la ley esos mismos derechos vienen plenamente a la existencia jurídica. (Fioravanti 2009: 131). No había zona de actuación del Estado que no se redujera a lo expresa y previamente establecido en la ley otorgada por el Legislador, traduciéndose toda forma de actuación en la centralidad de la ley.

De esta reducción del Derecho a la ley no era ajeno elámbito jurisdiccional; a tal punto que el rol del juez en el Estado decimonónico consistía en la aplicación de la ley vigente a la solución de las controversias sometidas a su decisión. Era tanta la reducción de la actividad judicial al texto formal de la ley a tal punto de sostener que "fue casi un credo jurídico que el juez debe limitarse a la aplicación de la ley mediante procesos mentales estrictamente lógicos y que debe abstenerse de propias decisiones arbitrarias; que está vinculado solamente al poder secular de la justicia reflejado en la ley, sin tener que representar ni practicar un poder social propio". (Bachof, 1985, p.23)

Las soluciones jurisdiccionales se determinaban a través de un mecanismo de rápida, segura y uniforme aplicación de la ley por parte de los jueces (Fioravanti, 2009, p. 115), siguiendo la convicción de que, una vez emanada la ley, los jueces debían aplicarla de manera cierta y uniforme sin que los jueces puedan inaplicarla. Así, el proceso era entendido como un simple trámite formal cuya regulación se encontraba literalmente prevista en la ley; se concebía como una actividad independiente y autónoma desprovista de todo valor; asumiendo un grado de autonomía que, en vez de ser un instrumento del derecho, este se convirtió en un instrumento del proceso. (Landa, 2018, p.495)

Se mantenía la idea del proceso como una mera consecución de actos procesales formales no vinculados al derecho sustantivo, donde la procedure era así el conjunto de formas que los ciudadanos debían seguir para obtener justicia y que los tribunales habían de observar para otorgarla, pero esas formas eran siempre las establecidas por la ley. Es la etapa de los Códigos y por ello también la de los procedimientos legalmente establecidos. (Priori, 2011 pp. 911-936)

De esta manera, la judicatura ordinaria estaba sometida al control del Parlamento, en la medida que el juez (a) era solamente vista como "la boca de la ley", ley que, como bien sabemos, era -y sobre todo en aquella épocala expresión por excelencia de la labor parlamentaria. La tarea de los jueces se limitaba así, únicamente a la composición de conflictos o la resolución de situaciones de incertidumbre, y su parámetro de evaluación era la ley y no la Constitución. (Espinoza-Saldaña, 2020, p. 95) 
Luego de la Segunda Guerra Mundial del siglo XX, se plantea un nuevo paradigma que importa el tránsito del Estado legislativo de derecho al Estado constitucional de derecho, concibiéndose como un auténtico cambio genético en el que "la ley, por primera vez en la época moderna, viene sometida a una relación de adecuación, y por tanto, de subordinación, a un estrato más alto de derecho establecido por la Constitución". (Zagrebelsky, 1999, p. 34)

La seguridad de los derechos fundamentales se alcanza ahora con su colocación en el núcleo fundamental de la Constitución, donde se encuentran esos principios de justicia que caracterizan de manera profunda el tipo histórico del Estado y de sociedad que está contenido en la Constitución, y que como tales preceden a la dimensión de la libre decisión política, que a ellos debe conformarse (Fioravanti 2009: 140). Así, los derechos fundamentales no tienen efecto por más tiempo en función de las leyes, sino que, a la inversa son las leyes las que tienen eficacia en función de los derechos fundamentales. (Haberle, 199, p. 264)

Se concibe el cambio en la relación entre Constitución y proceso, procurando la reintegración del derecho y el proceso, así como superando el positivismo jurídico procesal basado en la ley, con base en reconocer un rol tutelar al juez. Así, se parte de concebir a los propios derechos fundamentales como garantías procesales; es decir, otorgándoles implícitamente a los derechos humanos un contenido procesal de aplicación y protección concreta (Landa, 2018, p. 496). En este cambio es decisivo el papel activo de los jueces ordinarios, quienes ya no se limitan a aplicar la ley, sino, sobre todo, la Constitución.

Con este cambio de concepción, donde ya no es la ley la que condiciona los derechos fundamentales, sino la Constitución que contiene, los jueces cobran un protagonismo basilar. El Legislador no puede prever todas las aplicaciones posibles de la ley ni tiene un razonamiento puro y perfecto; carece de intensión respecto de muchas cosas en las cuales la ley tendría que posteriormente intervenir; $\mathrm{y}$, aún de los casos que ha previsto, hay muchas cosas que se le escapan, su intención no es completa, plena; y la expresión lingüística de tal intención no es en general suficientemente clara y precisa porque el lenguaje mismo es abierto y ofrece inevitablemente diferentes posibilidades de sentido. (Trazegnies, p. 587)

Así, el proceso ya no se reduce a una concepción positivista que se centra en la mera aplicación literal de las reglas procesales; sino que se empieza a entender como todo un conjunto de instituciones procesales que expresan verdaderos derechos fundamentales de garantía de cara a proteger 
otros derechos fundamentales, cuya validez y eficacia ya no dependen de reglas procesales autónomas, neutrales y/o científicas. Con razón Omar Sumaria señala que:

Insistir en la autonomía del derecho procesal, es hoy, como si el físico se preocupara por la demostración de la divisibilidad del átomo. La evolución de la naturaleza y del objetivo puramente técnico del sistema procesal, es al mismo tiempo, afirmación de su permeabilidad a los valores tutelados por el ordenamiento político-constitucional y jurídico material, los cuales buscan su efectividad a través de aquél, y realizan su inserción en el universo axiológico de la sociedad a la que se destina, formándose así el concepto de tutela jurisdiccional como derecho y valor constitucional. (2017, p. 113)

Se observa entonces que el proceso ha venido evolucionando, convirtiéndose ahora no solo en un mecanismo formal de protección de derechos fundamentales, sino, y sobre todo, en un auténtico derecho fundamental de naturaleza procesal; en el que la tutela judicial efectiva y el debido proceso se incorporan al contenido esencial de los derechos fundamentales, como elementos del núcleo duro de los mismos, permitiendo de esta manera que a un derecho corresponda siempre un proceso y a un proceso suponga siempre un derecho; pero que en cualquiera de ambos supuestos, su validez y eficacia la defina su respeto a los derechos fundamentales. (Landa, 2018, p. 52)

En el Estado constitucional de derecho es sumamente relevante que cualquier juez priorice como parámetro de actuación los valores y principios contenidas en la Constitución, en todas las causas que tiene bajo su conocimiento, desde que revisa el acceso a la judicatura, el trámite del proceso y hasta alcanzar una efectiva ejecución de lo sentenciado. Se obtiene así una verdadera tutela jurisdiccional efectiva que no se reduce a la respuesta formal de las pretensiones de los justiciables, sino a la real y verdadera satisfacción de las pretensiones; para lo cual es importante desterrar la idea de actividad mecánica y toda aplicación formal de las reglas procesales que impidan $\mathrm{u}$ obstaculicen el fin principal por el cual todo proceso es instaurado.

De esta forma, se logrará la efectividad de tutela judicial y se garantizará el derecho fundamental a la pensión alimenticia cuando el beneficiario titular del referido derecho pueda satisfacer oportunamente la pretensión material para lo cual acudió a la administración de justicia, esto, es sus necesidades básicas como la alimentación, salud, vestido, educación y todo lo necesario para un nivel de vida adecuado e integral. Para ello, resulta indispensable contar con instrumentos procesales idóneos que no 
obstaculicen la ejecución de la sentencia, así como un papel activo del juez en la interpretación de las disposiciones normativas que podrían dificultar la pronta ejecución, dejando atrás la idea de juez autómata propio del pensamiento positivista del proceso.

\section{LA EFICACIA DE LAS SENTENCIAS ALIMENTARIAS COMO MANIFESTACIÓN DEL DERECHO A LA TUTELA JURISDICCIONAL EFECTIVA}

La tutela judicial y el debido proceso se incorporan al contenido esencial de los derechos fundamentales, como elementos del núcleo duro de los mismos, permitiendo de esta manera que a un derecho corresponda siempre un proceso y que un proceso suponga siempre un derecho, pero en cualquiera de ambos supuestos, su validez y eficacia la defina su respeto a los derechos fundamentales (Landa, 2018, p.496). De esta manera, la tutela jurisdiccional es concebida como un auténtico derecho fundamental de naturaleza procesal a través de la cual se busca protección real de los derechos fundamentales de la persona humana.

Para que la tutela judicial realmente garantice la protección de los derechos fundamentales tiene que ser efectiva. La efectividad es algo consustancial al derecho a la tutela judicial, puesto que, si no fuera efectiva, por definición no sería tutela; ya que de nada servirían al ciudadano unas excelentes resoluciones judiciales que no se llevarán a la práctica. Efectividad quiere decir que no se le hurte al ciudadano una resolución al amparo de formalismos exagerados; efectividad quiere decir que la resolución dictada realmente decida el problema planteado. (Chamorro, 1994, p. 276)

En ese sentido, la efectividad de la tutela judicial no se agota con el acceso a la jurisdicción, a contar con un debido proceso, o a obtener una sentencia fundada en derecho, sino, y sobre todo, cuando se cumpla en los hechos y de manera oportuna lo mandado en la sentencia. Lo que se persigue a través de un proceso no es solamente que los tribunales dicten sentencia; sino que lo mandado en la decisión final sea cumplido. La ejecución procesal constituye en cierto sentido el punto culminante de la realización del derecho; de manera que, el deber de cumplir lo ordenado por los tribunales se haya sancionado como un deber constitucional. (Gonzáles, 1980, p. 223)

La ejecución de la sentencia constituye una manifestación del derecho fundamental a la tutela jurisdiccional efectiva, reconocida por el artículo 139, inciso 2 de la Constitución, cuando establece que ninguna autoridad puede dejar sin efecto resoluciones que han pasado en autoridad de cosa juzgada ni 
retardar su ejecución. Al respecto, el Tribunal Constitucional ha establecido en la STC N.o 15-2001-AI, 16-2001-AI, 4-2001-AI, lo siguiente:

El derecho a la ejecución de las resoluciones judiciales constituye, pues, una concreción específica de la exigencia de efectividad que garantiza el derecho a la tutela jurisdiccional y que no se agota allí, pues por su propio carácter tiene una vis expansiva que se refleja en otros derechos constitucionales de orden procesal (v. gr. derecho a un proceso que dure un plazo razonable). El derecho a la efectividad de las resoluciones judiciales garantiza que lo decidido en una sentencia se cumpla, y que la parte que obtuvo un pronunciamiento de tutela, a través de la sentencia favorable, sea repuesta en su derecho y compensada, si hubiere lugar a ello, por el daño sufrido (...).

En el caso Furlan y familiares vs. Argentina, la Corte Interamericana de Derechos Humanos ha señalado que:

(...)elprincipiodetutelajudicialefectiva requierequelos procedimientos de ejecución sean accesibles para las partes, sin obstáculos o demoras indebidas, a fin de que alcancen su objetivo de manera rápida, sencilla e integral. (...) en un ordenamiento basado sobre el principio del Estado de Derecho todas las autoridades públicas, dentro del marco de su competencia, deben atender las decisiones judiciales, así como dar impulso y ejecución de las mismas sin obstaculizar el sentido y alcance de la decisión ni retrasar indebidamente su ejecución.

De esta forma, la ejecución de la sentencia constituye parte importante del proceso; toda vez que, en ella se determinará la realización concreta y real de las pretensiones planteadas por las partes. Es en dicha etapa procesal donde los justiciables verán si realmente valió la pena haber iniciado y seguido todo el largo camino del proceso, pues de nada serviría haber logrado la ansiada sentencia si esta no se ejecuta en sus propios términos y en forma oportuna.

Para que la sentencia pueda ser ejecutada y logre satisfacer las pretensiones de los justiciables, es importante que el juzgador cuente con reglas idóneas capaces de viabilizar de manera rápida y sencilla la efectiva ejecución de lo sentenciado.

La falta de reglas idóneas y eficaces para la ejecución de sentencias en modo alguno implicaría que el juez se quede de brazos cruzados frente a los requerimientos de ejecución de los justiciables, pues la omisión del legislador 
no puede justificar la omisión del juez (Marinoni, 2016, p. 27). Sin embargo, es un hecho cierto que la falta de instrumentos normativos idóneos implica dificultades al momento de ejecutar la sentencia; si esto es así, la situación se vuelve más difícil cuando las propias reglas establecidas por el legislador resultan incongruentes y contradictorias entre unas y otras, evidenciando la existencia de serios obstáculos en la actuación del juez de ejecución, en perjuicio de los derechos fundamentales de los justiciables.

Estas deficiencias y obstáculos normativos en la actuación del juez se evidencian en los procesos de alimentos en etapa de ejecución, lo que viene ocasionando que las sentencias alimentarias no puedan ser ejecutadas en forma sencilla, rápida y oportuna, perjudicando gravemente a los beneficiarios, en su mayoría perteneciente a la infancia, en la satisfacción de su derecho fundamental a la pensión alimenticia.

\section{ELVERDADEROPROBLEMA ENLOSPROCESOSDEALIMENTOS ¿SU ACCESO, TRÁMITE PROCESAL O EJECUCIÓN?}

A lo largo de todo este tiempo, se puede observar variados textos y opiniones de especialistas respecto de los procesos de alimentos. La mayoría de dichos textos se decantan por analizar situaciones previas al trámite del proceso y los criterios a tener en cuenta para establecer el monto de la pensión alimenticia en la sentencia. Se vienen emitiendo directivas para facilitar el acceso a la administración de justicia, contar con celeridad procesal y obtener la sentencia judicial en el breve plazo. Claro ejemplo es la Directiva N 007-2020-CE-PJ "Proceso Simplificado y Virtual de Pensión de Alimentos para Niña, Niño y Adolescente", aprobada por Resolución Administrativa $\mathrm{N}^{\circ}$ 000167-2020-CE-PJ, publicado el 18 de junio de 2020, en el diario oficial El Peruano.

Establecer fórmulas sencillas de acceso a la justicia y celeridad procesal para obtener la sentencia de alimentos oportunamente es valioso e importante; por cuanto, se trata de pretensiones alimentarias planteadas, en la mayoría de los casos, por personas en situación de vulnerabilidad que muchas veces no conocen los mecanismos institucionales para accionar en búsqueda de tutela de sus derechos.

Se debe tener en cuenta incluso la dimensión pre procesal del derecho de acceso a la justicia que implica el previo conocimiento del derecho de las personas, identificándolo plenamente para accionarlos ante los tribunales de justicia y contra los responsables de su afectación. Es importante que las personas puedan reconocer la existencia de un problema, identificar que tiene 
una naturaleza jurídica, identificar a la persona o entidad responsable o que debe cumplir una obligación en relación con el mismo, así como convertir el problema en una demanda o reclamo por la vía pertinente. (Ramírez, 2018, pp. 321-343)

Sin embargo, a pesar de la importancia de la identificación y reconocimiento de los derechos y de los medios institucionales para acceder al sistema de justicia, podemos sostener, sin temor a equivocarnos, que no resulta suficiente para garantizar una verdadera y efectiva protección de las pretensiones alimentarias; toda vez que, si bien, gracias a las diversas disposiciones de simplificación y celeridad del proceso de alimentos se puede expedir una sentencia oportuna, esta no logra ejecutarse en el tiempo que demanda las exigencias del derecho fundamental de los alimentos. No obstante ello, poco se ha dicho respecto de la problemática de la ejecución de las sentencias alimentarias; pareciera que el proceso de alimentos cumpliría su finalidad con la emisión de la sentencia que fija el monto de la pensión alimenticia; que la tutela jurisdiccional efectiva de las prestaciones alimentarias se agotaría con el dictado de la sentencia.

El problema de los procesos de alimentos no se encuentra solo en el aspecto pre procesal, en su trámite o en la expedición de la sentencia. En realidad, el verdadero problema se presenta con el inicio de la ejecución de la sentencia que fija la pensión alimenticia; desde ese momento se inicia el verdadero calvario para quien obtuvo la sentencia debido al incumplimiento del deudor alimentario. Darle poca importancia a la fase de ejecución de los procesos de alimentos implicaría desconocer el fin que se busca con dichos procesos, alejándonos cada vez más de una verdadera tutela efectiva del derecho fundamental a la pensión alimenticia.

\section{EL VERDADERO CALVARIO DE LOS JUSTICIABLES EN LOS PROCESOS DE ALIMENTOS QUE NO SE VE O NO SE QUIERE VER}

Hemos venido sosteniendo que el problema central de los procesos de alimentos se encuentra en la fase de ejecución de la sentencia.

En el Informe $\mathrm{N}^{\circ}$ 001-2018-DP/ACC, publicado el mes de julio de 2018, la Defensoría advirtió que solo el 38,9\% de procesos con sentencia estimatoria lograron ser ejecutados frente a un 50\% que no lograron alcanzar ejecución. También evaluó el tiempo que transcurrió hasta la ejecución de la sentencia; es decir, cuánto tardó en hacerse efectivo el goce de una pensión de alimentos, conforme al siguiente cuadro: 


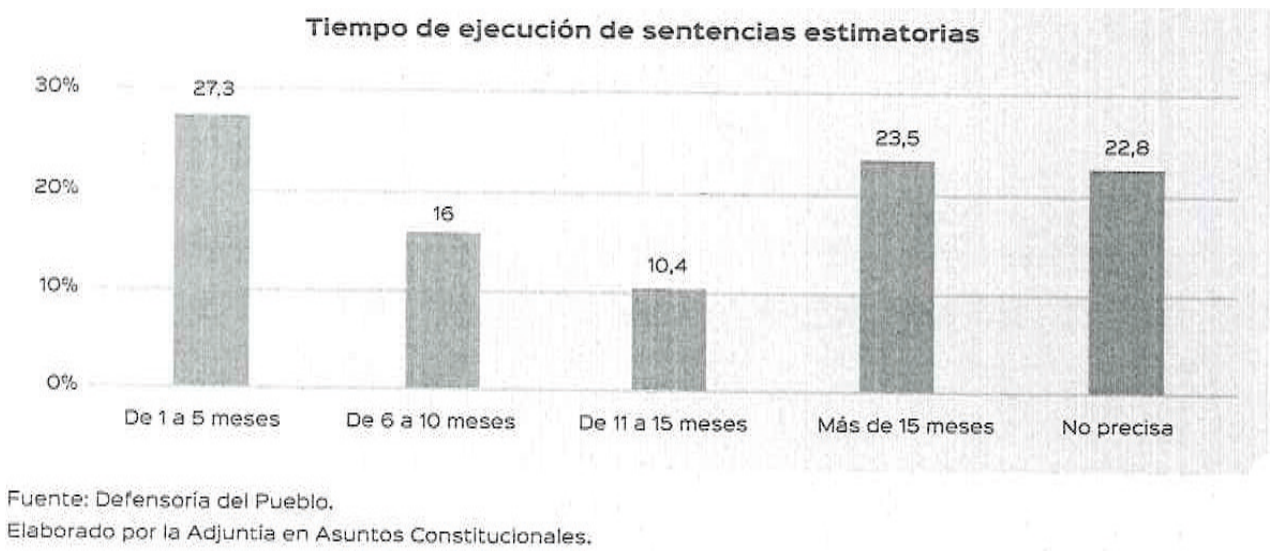

Como se observa, el 27,3\% de los casos la ejecución demoró entre uno y cinco meses; mientras que el 16\% tuvieron que transcurrir entre seis y diez meses; el 10.4\% tuvo una duración de 11 a 15 meses (hasta 01 año con 03 meses); y, en el 23,5\% de los procesos, la sentencia fue ejecutada en más de 15 meses (en más de 01 año con 03 meses).

Si se hace una comparación con el tiempo de duración de los procesos en primera instancia ${ }^{4}$, podemos advertir que para el caso de la ejecución de las sentencias alimentarias, estas solo lograron ejecutarse en un $38.9 \%$ del total de las sentencias emitidas en primera instancia; y sobre todo, el tiempo que transcurrió hasta que logren ejecutarse con el pago efectivo de las pensiones alimenticias es mayor al tiempo que demora el trámite del proceso hasta la expedición de la sentencia.

Con ello podemos reiterar que la problemática en los procesos de alimentos se encuentra en su fase de ejecución por el tiempo o retardo en efectivizarse la sentencia; de manera que, hemos considerado oportuno desarrollar algunas ideas que podrían constituir las causas que estarían retardando excesivamente la ejecución de las sentencias alimentarias.

\subsection{ANTINOMIAS EN LAS REGLAS DE EJECUCIÓN DE SENTENCIAS DE LA PENSIÓN DE ALIMENTOS}

En principio, es importante precisar que la incoherencia o incompatibilidad de las consecuencias jurídicas entre dos normas constituye

\footnotetext{
En relación al tiempo de duración del proceso en primera instancia, el informe advirtió que el 28,2\% de procesos que culminaron con sentencia han durado entre 181 a 365 días, es decir, entre seis meses y un año. En el 19,3\% de los casos el proceso se prolongó por encima del año, pese a que las vías procedimentales con las que se debe tramitar el proceso de alimentos tienen la intención de ser céleres y expeditivas.
} 
casos de antinomias. Hablamos de antinomia o contradicción cuando dos reglas jurídicas correlacionan el mismo caso de soluciones normativas incompatibles (Rodenas, 2012, p. 21-51).

Según refiere Guastini, puede ocurrir -en realidad ocurre continuamente- que dos normas dispongan para un mismo supuesto de hecho (una circunstancia o una combinación de circunstancias) singular y concreto, consecuencias jurídicas incompatibles entre sí (2018, p.125). En ese sentido, el jurista italiano clasifica las antinomias de tipo abstracto y concreto; y refiere que:

Se tiene una antinomia en concreto cuando, en sede de aplicación, se advierte que dos normas, que abstractamente no entran en conflicto, vinculan, no obstante consecuencias jurídicas incompatibles a un mismo supuesto de hecho concreto. Esto ocurre cada vez que un supuesto de hecho (...) queda comprendido simultáneamente en dos clases de supuestos de hechos conceptualmente independientes para lo que el derecho dispone consecuencias jurídicas incompatibles. De modo que la antinomia puede ser identificada solo en sede de aplicación de las normas a un caso concreto (al que, precisamente por casualidad ambas son aplicables) (2018, p. 127-128)

Nuestro ordenamiento jurídico procesal no es ajeno a incoherencias normativas; aquellas las podemos encontrar en las disposiciones contenidas en los artículos 566 y 566-A del Código Procesal Civil (En adelante CPC), aplicables al caso de la ejecución de las sentencias en los procesos de alimentos. Así, el artículo 566 del CPC, prescribe lo siguiente:

La pensión de alimentos que fije la sentencia debe pagarse por período adelantado y se ejecuta aunque haya apelación. En este caso, se formará cuaderno separado. Si la sentencia de vista modifica el monto, se dispondrá el pago de este.

Por su parte, el artículo 566-A del mismo código prescribe que:

Si el obligado, luego de haber sido notificado para la ejecución de sentencia firme, no cumple con el pago de los alimentos, el Juez, a pedido de parte y previo requerimiento a la parte demandada bajo apercibimiento expreso, remitirá copia certificada de la liquidación de las pensiones devengadas y de las resoluciones respectivas al Fiscal Provincial Penal de Turno, a fin de que proceda con arreglo a sus atribuciones. 
Setratadedos disposiciones procesalesantinómicas.Delainterpretación de la primera tenemos que la sentencia expedida en un proceso de alimentos se ejecuta independientemente del recurso de apelación que se interponga en su contra. La apelación concedida no tendría efectos suspensivos sobre la sentencia y esta tendría que ejecutarse sin más trámite; es decir, ante el incumplimiento del pago de la pensión alimenticia, se tendría que iniciar la ejecución de la sentencia con la propuesta de las pensiones devengadas para su liquidación y posterior aprobación.

Sin embargo, la disposición contenida en el artículo 566-A del mismo código, exige que la sentencia de alimentos tenga la calidad de firme para que recién pueda ejecutarse. No podría iniciarse los actos de ejecución si la sentencia no adquiere la calidad de firme; de manera que, tampoco podría remitirse las copias certificadas de las pensiones devengadas al Fiscal Provincial de Turno. Para remitir las referidas copias certificadas se requiere previamente la aprobación de la liquidación de las pensiones devengadas, lo cual no podría determinarse si no se cuenta con sentencia firme.

Esta incompatibilidad normativa de carácter procesal no es advertida en la propia judicatura. En la práctica judicial se viene aplicando la segunda disposición normativa, casi invalidando la primera. No se inicia la ejecución de la sentencia debido a que no se cuenta con sentencia firme, sea consentida o ejecutoriada. Tampoco ha merecido algún pronunciamiento por la Comisión Revisora que publicó el Proyecto de Reforma del Código Procesal Civil, por Resolución Ministerial N 0070-2018-JUS, de fecha 05 de marzo de 2018. Si revisamos las disposiciones especiales contenidas en el Subcapítulo 1, del Capítulo II, del Título III del proyecto de reforma, se puede observar que las disposiciones citadas son las mismas que fueron modificadas e incorporadas por Ley $\mathrm{N}^{\circ} 28439$, publicado con fecha 28 de diciembre de 2004. Al parecer, las reglas procesales en materia de ejecución de sentencias alimentarias estarían marchando bien.

Antinomias o no, lo cierto es que estamos frente a una incongruencia normativa de carácter procesal que no ha llamado la atención que se merece al legislador y la opinión jurídica y judicial. De esta forma, se incumple el deber del legislador de establecer procedimientos de ejecución accesibles para las partes y sin obstáculos y demoras indebidas, conforme lo establecido la Corte Interamericana de Derechos Humanos en el caso Furlan y familiares vs. Argentina. 


\subsection{LA EJECUCIÓN ANTICIPADA DE LA SENTENCIA DE ALIMENTOS EN CUADERNO SEPARADO}

De acuerdo con lo prescrito por el artículo 566 del CPC, la pensión de alimentos que fija la sentencia se ejecuta aunque haya apelación. Ya se ha advertido líneas arriba sobre la incongruencia presentada en las normas procesales; por cuanto, el artículo 566-A del CPC, establece que para la efectiva ejecución se exige que la sentencia se encuentre firme. Sin embargo, la primera norma citada, agrega que en dicho caso (para ejecutar la sentencia aunque haya sido apelada) se formará cuaderno separado; para lo cual se ordena al demandado abrir una cuenta de ahorro a nombre de la demandante para el pago y cobro de la pensión alimenticia ordenada.

La primera observación a la norma consiste precisamente en que se ordena al demandado abrir una cuenta de ahorros a favor de la demandante. Siendo el demandado quien debe efectuar los pagos por pensiones de alimentos poco interés tiene en abrir dicha cuenta de ahorros; excusándose en que al no haber sentencia firme por haberse interpuesto recurso de apelación no resulta aún exigible el pago y por ende la apertura de cuenta alguna. Frente a esta situación, es la propia demandante quien recurre, por lo general, al Banco de la Nación para que se le otorgue una cuenta de ahorros que luego se comunica al demandado para el cumplimiento del pago de las pensiones alimenticias.

De otrolado, la norma dispone que para ejecutar la sentencia se forma un cuaderno separado de ejecución anticipada. Se entiende entonces que ante el incumplimiento del pago de las pensiones alimenticias la demandante podrá (o podría) iniciar los actos de ejecución necesarios para la liquidación de las pensiones devengadas y de los intereses legales en el cuaderno de ejecución anticipada, en los términos establecidos en la sentencia aunque hubiese sido apelada. Sin embargo, como se ha anotado, no es posible ejecutar una sentencia que se encuentra en apelación ya que no tiene la calidad de firme.

La sentencia de alimentos constituye el título que contiene la obligación de pago de una suma de dinero por concepto de pensión de alimentos; siendo así, para la ejecución de la sentencia se hace necesario que la obligación (pago de la pensión de alimentos) resulte exigible; es decir, no debe encontrarse sujeta a ninguna condición o modo. Sin embargo, el artículo 566-A del CPC, habría establecido una condición legal para iniciar la ejecución de la sentencia alimentaria al exigir que adquiera la calidad de firme, pues establece que el obligado se encuentre notificado para la ejecución de la sentencia firme. En tanto no se cumpla esta condición (sentencia firme) no existe obligación 
alimentaria exigible; por ende, no se podría iniciar materialmente los actos de ejecución para la liquidación de las pensiones devengadas en el cuaderno de ejecución anticipada.

Esta situación impide que jueces y juezas puedan iniciar materialmente la ejecución de las sentencias alimentarias, conforme a lo prescrito por el artículo 568 del CPC, según el cual, concluido el proceso, sobre la base de la propuesta que formulan las partes, el Secretario del Juzgado practicará la liquidación de las pensiones devengadas y de los intereses computados a partir del día siguiente de la notificación de la demanda. De esta forma, no es posible acudir a la justicia penal por el delito de Omisión a la Asistencia Familiar y tampoco la inscripción en el Registro de Deudores Alimentarios Morosos - REDAM, en tanto es necesario la existencia de deuda exigible por un periodo determinado, lo que se obtiene cuando se aprueba la liquidación de las pensiones devengadas que se inicia con la ejecución de la sentencia firme.

Por consiguiente, el cuaderno de ejecución anticipada de la sentencia de alimentos, que debe formarse en aplicación del artículo 566 del CPC, no constituye instrumento idóneo para efectivizar realmente el pago de las pensiones alimenticias ante la renuencia del deudor alimentario. A lo mucho se podría apercibir con la imposición de multas al deudor renuente; aunque, en efecto, ello no protege y satisface de manera real y efectiva los derechos e intereses declarado en sentencia a favor del beneficiario con la pensión. El cuaderno de ejecución anticipada resulta útil cuando los pagos de las pensiones se realizan a través de descuentos que el empleador realiza de las remuneraciones mensuales del obligado; o cuando el obligado conscientemente cumple con los pagos y comunica al juzgado adjuntando los documentos pertinentes.

En situaciones de incumplimiento reiterado del pago de las pensiones alimenticias, el cuaderno de ejecución anticipada no cumple en realidad la finalidad para cual debe ser formado; esto es, para exigir concretamente y con resultados efectivos el pago de la pensión de alimentos; dado que, únicamente se puede reiterar, las veces que sea necesario, el cumplimiento de pago de la pensión al obligado, bajo los apercibimientos que en modo alguno satisfacen el derecho a obtener en forma oportuna y sencilla la pensión alimenticia. 


\subsection{RECHAZOS INDEBIDOS DE LA PROPUESTA DE LIQUIDACIÓN DE PENSIONES DEVENGADAS}

Una vez obtenido la sentencia firme, sea porque quedó consentida o porque fue resuelta por el superior en vía de apelación (ejecutoriada), las y los demandantes inician la ejecución de la sentencia con la presentación de la propuesta para la liquidación de las pensiones devengadas, conforme lo establece el artículo $568 \mathrm{del} \mathrm{CPC.} \mathrm{Sin} \mathrm{embargo,} \mathrm{cometen} \mathrm{algunos} \mathrm{errores} \mathrm{al}$ momento de formularla, pues afirman y proponen que los devengados deben liquidarse desde la fecha de la presentación de la demanda de alimentos; otras veces, no precisan el periodo de la liquidación, o no hacen un adecuado cálculo aritmético lo que arroja como propuesta un monto devengado distinto al que realmente corresponde.

Los errores advertidos muchas veces motivan que no se acepte la propuesta de pensiones devengadas para su liquidación; de manera que, el órgano jurisdiccional rechaza y devuelve a la parte proponente para que la corrija y la formule adecuadamente; sin tener en cuenta que en los procesos de alimentos una gran cantidad de justiciables acuden a la vía judicial sin la asesoría técnico jurídica de Abogado, lo que se evidencia, sobre todo, en la etapa de ejecución de la sentencia; razón por la cual, la exigencia de una correcta presentación de la propuesta de devengados deviene en excesiva y afecta el derecho a obtener de manera oportuna la pensión alimenticia declarada en sentencia judicial.

Lo que la ley establece expresamente es que las partes presenten solo la propuesta para la liquidación de pensiones devengadas. La liquidación de lo devengado y de los intereses legales se practica en el juzgado que ejecuta la sentencia; de manera que, somos de la opinión que rechazar la propuesta de devengados por algunos errores relacionados con la fecha de inicio de la liquidación o el periodo devengado, exigiendo el monto correcto, implica que la parte ya no presenta una propuesta sino la liquidación en sí misma de las pensiones devengadas y de los intereses legales, contraviniendo lo prescrito por el artículo 568 del CPC. Rechazar y devolver la propuesta de lo devengado por el incumplimiento de pago del deudor alimentario, exigiendo a la parte vencedora de un proceso de alimentos una exacta y detallada propuesta para su liquidación, contraviene el derecho a una ejecución sencilla y rápida.

Por ello, consideramos que ante cualquier error en la presentación de la propuesta de devengados no debería implicar su no aceptación y su devolución, sino la corrección de oficio por el juzgado de ejecución al 
momento de practicar la liquidación, pues es quien conoce de las actuaciones recaídas en el proceso y quien tiene el expediente a la vista. Lo contrario atenta el principio de la tutela judicial efectiva, que conforme se ha desarrollado, requiere que los procedimientos de ejecución sean accesibles para las partes, sin obstáculos o demoras indebidas, a fin de que alcancen su objetivo de manera rápida, sencilla e integral. Corresponde a la autoridad judicial, dentro del marco de su competencia, atender las decisiones judiciales, dar impulso y ejecutar lo sentenciado sin obstaculizar ni retrasar indebidamente su ejecución.

También es importante agregar que se ha vuelto práctica común el excesivo empleo de los llamados córrase traslado. Cada vez que se presenta la propuesta de pensiones devengadas se traslada previamente al demandado para que absuelva en el plazo de tres días. Con o sin la absolución, si la parte interesada no reitera su pedido para que se practique la liquidación de pensiones devengadas y de los intereses, esta no se realiza. Y si hay observación del demandado a la propuesta, se corre traslado a la demandante para que, de igual forma lo absuelva. Una vez practicada la liquidación de las pensiones devengadas por el Secretario del Juzgado, nuevamente se pone en conocimiento de dicha liquidación a las partes, y ante cualquier observación nuevamente se corre traslado a la parte contraria.

Estas disposiciones judiciales vienen siendo equivocadamente interpretadas a partir de artículo 568 del CPC, en cuanto prescribe que la liquidación se practica sobre la base de la propuesta que formulen las partes. Somos de la opinión que si bien la norma no establece correr traslado en cada momento del proceso, debería modificarse para que la liquidación de las pensiones devengadas y los intereses legales se practiquen sin la necesaria presentación de la propuesta referida; siendo suficiente que se indique el periodo a liquidarse. De esta forma, lo que se pondría en conocimiento de la partes es la liquidación practicada en el juzgado de ejecución para que, previa absolución u observación de las partes, se determine su aprobación total o parcial; evitando una excesiva demora en la aprobación de la liquidación de lo devengado.

\subsection{LA NOTIFICACIÓN DEL REQUERIMIENTO DE PAGO DE LAS PENSIONES DEVENGADAS AL DEMANDADO}

Por disposición del artículo 566-A del CPC, aprobada la liquidación de las pensiones devengadas se requiere al obligado para que cumpla con el pago en el plazo de tres días; bajo el apercibimiento de remitirse copia certificada al Ministerio Público para la acusación penal por el delito de omisión a la asistencia 
familiar, tipificado por el artículo 149 del CP; dicho acto sustituye el trámite de la interposición de la denuncia penal. Ante el incumplimiento de pago de la deuda aprobada, y previa notificación al domicilio procesal del obligado, el Juez remite copia certificada de la liquidación de las pensiones devengadas y de las resoluciones respectivas al Fiscal Provincial Penal de Turno.

Al respecto, es importante anotar que un sector de la judicatura dispone notificar solo al domicilio procesal o casilla electrónica del Abogado del obligado fijada en el proceso. Así, se observa que en el Exp. N 5804-20180, por resolución 06, de fecha 10 de abril de 20195 , se resolvió:

... Aprobar la Liquidación ...; en consecuencia, requiérase al emplazado ... para que dentro del plazo del tercer día de notificado cumpla con cancelar su pago, bajo apercibimiento de ser denunciado por el delito de misión a la asistencia familiar, debiendo notificársele al demandado en su domicilio procesal que indicó. .... (Resaltado agregado).

En el Exp. $\mathrm{N}^{\circ}$ 0841-2010-0, por resolución 31 de fecha 02 de mayo de $2019^{6}$, se dispuso:

... Tener por bien notificada a la parte demandada ... en su domicilio procesal constituido por la casilla electrónica ..., perteneciente al letrado ..., el cual ha designado como abogado defensor por la propia parte demandada; y en concordancia con lo argumentado se dispone: REMITIR a la Quinta Fiscalía Provincial Mixta de San Juan De Lurigancho, ..."7.

Otro sector de la jurisdicción exige que la notificación, además de la dirigida al domicilio procesal o casilla electrónica, debe notificarse necesariamente al domicilio real del demandado que figura en la Ficha RENIEC. Así, en el Exp. N 480-2017-0, por resolución número 11, de fecha 27 de mayo de $2019^{8}$, se resolvió:

\footnotetext{
Este proceso se encuentra en fase de ejecución ante el Quinto Juzgado de Paz Letrado de San Juan de Lurigancho. Este proceso también viene tramitándose en etapa de ejecución en el Quinto Juzgado de Paz Letrado de San Juan de Lurigancho.

En esta resolución se dispuso con ratio decidendi lo siguiente: De lo expresado en los literales precedentes se puede afirmar categóricamente que el demandado señalo un domicilio procesal y que ha tenido la oportunidad de presentar los recursos que estimo pertinente en virtud de ser patrocinado por letrado y por haber sido emplazado en el domicilio procesal que indico, y posteriormente esta judicatura a partir de la resolución número 27 ha dispuesto emplazar a la parte demandada únicamente en la Casilla Electrónica del abogado patrocinante que el propio demandado ha indicado; no pudiendo esta judicatura soslayar ese hecho, a pesar de que la parte emplazada haya dejado de presentar escritos. Siendo además indiscutible el hecho de que ni el abogado defensor ha indicado que ya no patrocina a la parte emplazada, ni la parte demandada ha manifestado a esta judicatura que ya no cuenta con los servicios del letrado que ella misma nombro.

8 Este proceso fue tramitado en el Primer Juzgado de Paz Letrado de San Juan de Lurigancho.
} 
... Aprobar la Liquidación de las Pensiones Alimenticias Devengadas, ...: REQUIÁRESE al demandado ..., a efectos de que ... cumpla con hacer efectivo su pago, bajo apercibimiento de remitirse copias certificadas de lo actuado al Ministerio Público .... Debiendo la presente resolución ser notificada al demandado tanto en su domicilio real como el procesal ....

Asimismo, en el Exp. № 0355-2004-0, por resolución número 92, de fecha 07 de setiembre de $2016^{9}$, se resolvió:

Aprobar la Liquidación de Pensiones Alimenticias Devengadas ...; en consecuencia, REQUIERASE al demandado ... cumpla con hacer efectivo su pago, bajo apercibimiento de ley en caso de incumplimiento .... Debiendo la presente resolución ser notificada al demandado tanto a su domicilio real como procesal ....

El problema persiste cuando vez remitido las copias de la liquidación de las pensiones devengadas y de los demás actos procesales al Ministerio Público, la Fiscalía vieneexigiendo que el requerimiento de pago sea notificado al domicilio real y procesal del obligado. La omisión en la notificación al domicilio real del obligado no podría dar inicio al cumplimiento de sus atribuciones; es decir, el fiscal no podría iniciar la acusación penal por el delito tipificado en el artículo 149 del CP; por cuanto, no se tendría certeza que el demandado haya tomado conocimiento del requerimiento de pago; y se procede, por tanto, con la devolución de las copias de la liquidación al juzgado de ejecución de las sentencias alimentarias:

Se advierte que por resolución ... se aprueba la liquidación de pensiones devengadas y además se requiere el pago de esta deuda ..., sin embargo, solo se ha adjuntado el cargo de notificación de esta resolución cursado al domicilio procesal, sin que se adjunte documento que acredite haberse notificado el requerimiento también al domicilio real, por lo que no tenemos la certeza que el demandado haya tomado conocimiento de este requerimiento; lo que imposibilita a esta Fiscalía determinar el ejercicio de la acción penal; al no haberse recaudado el documento que acredite la notificación de la resolución ... al domicilio real del demandado, corresponde devolver el cuadernillo de copias certificadas ... ${ }^{10}$;

Este proceso se encuentra en etapa de ejecución ante el Tercer Juzgado de Paz Letrado del Módulo Básico de San Juan de Lurigancho.

10 Ingreso $N^{\circ}$ 651-2019, de fecha 05 de junio de 2019. Distrito Fiscal de Lima Este. Quinta Fiscalía Provincial Mixta S.J.L. 
Para la Fiscalía es requisito indispensable para inicio de la acusación penal por el delito de la omisión a la asistencia familiar, que la notificación del requerimiento de pago de la deuda alimentaria sea notificada al domicilio real, esto es, al que figura en la Ficha RENIEC del obligado; caso contrario no se podría determinar el ejercicio de la acción penal. Sin embargo, la exigencia de la notificación del requerimiento de pago al domicilio real del demandado constituye una de las principales razones de la demora excesiva de la ejecución de las sentencias alimentarias; toda vez que, el demandado no se siente conminado por la justicia penal al pago de las pensiones devengadas; de manera que, a continuación daremos algunas ideas por las que no debería presentarse tal exigencia.

\section{A. INVALIDA LAS NOTIFICACIONES EFECTUADAS EN EL JUZGADO DE EJECUCIÓN}

La norma jurídica que se invoca a nivel Fiscalía para exigir la notificación al domicilio real, es el artículo 155 del CPC; así, sostienen que el acto de notificación tiene por objeto poner en conocimiento de los interesados el contenido de las resoluciones judiciales, las que solo producen efectos en virtud de notificación hecha con arreglo a lo dispuesto por el Norma Procesal.

Sin embargo, debe advertirse que mediante Disposición Complementaria de la Ley $\mathrm{N}^{\circ}$ 30229, publicado el 12 de julio de 2014, en el marco del Adecuado Uso de las Tecnologías de la Información y Comunicaciones en los Servicios de las Notificaciones de las Resoluciones Judiciales, se incorporan al Texto Único Ordenado de la Ley Orgánica del Poder Judicial, entre otros, los artículos 155-A, 115-B, 155-C, 155-D y 155-E. Estas disposiciones establecen que la notificación electrónica es un medio alternativo a la notificación por cédula y se deriva a casilla electrónica de manera obligatoria en todos los procesos contenciosos y no contenciosos tramitados ante los órganos jurisdiccionales del Poder Judicial; de manera que es requisito de admisibilidad que las partes procesales consignen en sus escritos postulatorios la casilla electrónica asignada por el Poder Judicial.

De esta forma, el artículo 155-C, de la Ley Orgánica del Poder Judicial, incorporado por la Ley $\mathrm{N}^{\circ} 30229$, prescribe que la resolución judicial surte efectos desde el segundo día siguiente en que se ingresa su notificación a la casilla electrónica, con excepción de las que son expedidas y notificadas en audiencias y diligencias especiales. Asimismo, por Resolución Administrativa 260-2015-CE-PJ, de fecha 19 de agosto de 2015, dispuso la aprobación de la Directiva 006-2015- CE-PJ, denominada "Lineamientos para el diligenciamiento de las notificaciones electrónicas", que estableció 
que la casilla electrónica constituye domicilio procesal electrónico, a efectos de optimizar el servicio de notificaciones judiciales, directiva que es de aplicación y cumplimiento obligatorio en todas las instancias jurisdiccionales y administrativas del Poder Judicial en donde se encuentre implementado el servicio de notificaciones electrónicas.

De esta forma, cuando los emplazados se apersonan al proceso de alimentos, sea al contestar la demanda o en cualquier posterior escrito de apersonamiento, el abogado que ejerce la defensa señala su casilla electrónica para que se le notifiquen todas las resoluciones judiciales emanadas en el proceso, conforme a las normas vigentes citadas; de manera que, las notificaciones de la resolución judicial de requerimiento de pago de las pensiones devengadas derivada a la casilla electrónica del abogado del demandado se encuentran dentro del marco de las normas vigentes que le otorgan validez y plenos efectos. No se podría sostener, entonces, que dichas notificaciones no otorgan certeza del conocimiento que haya tomado el demandado sobre el requerimiento de pago de las pensiones devengadas.

Asimismo, al desconocer en sede de fiscalía las notificaciones electrónicas del requerimiento de pago efectuadas por el juzgado de ejecución, se estaría actuando como sede de instancia, invalidando y dejando sin efecto todas las notificaciones electrónicas realizadas en el proceso. El Ministerio Público no es sede de instancia ni órgano revisor en los procesos de alimentos; de manera que, no es legalmente posible que invaliden o dejen sin efecto las notificaciones electrónicas y exigir la notificación al domicilio real del obligado, menos que dispongan la devolución de las copias certificadas al juzgado de ejecución; por cuanto, con ello se afectan los derechos e intereses de los menores beneficiarios a la obtención de una pronta satisfacción del derecho a las pensiones alimenticias.

En ese sentido, somos de la opinión que cuando se trata de la notificación del requerimiento de pago al demandado, es válida y con plenos efectos la notificación a la casilla electrónica del abogado, en conformidad con las normas incorporadas a la Ley Orgánica del Poder Judicial; razón por la cual, no resulta exigible la notificación al domicilio real del obligado que figura en la Ficha RENIEC.

\section{B. SE ALEJA DE LOS CRITERIOS, AUNQUE NO VINCULANTES, DE ALGUNOS PLENOS JURISDICCIONALES DISTRITALES}

Esta problemática ha sido, incluso, materia de plenos jurisdiccionales distritales en algunas cortes del país. En el II Pleno Jurisdiccional Distrital en 
Materia Constitucional y Familia, realizada en la Corte Superior de Justicia de Huancavelica, con fecha 29 de diciembre de 2008, se planteó la siguiente pregunta: ¿Cuál es el acto de notificación válido respecto a las resoluciones de requerimiento de pago de alimentos devengados para exigir su cumplimiento? En conclusión plenaria de los jueces de esta corte, se aprobó por mayoría la postura de la primera posición: “La notificación es válida (o suficiente) en el domicilio procesal del obligado demandado".

Asimismo, en el Pleno Jurisdiccional Distrital Penal de la Corte Superior de Justicia de Junín, realizada con fecha 29 de diciembre de 2015, los jueces de dicha corte se plantearon como Tema $\mathrm{N}^{\circ}$ 02: Notificación del requerimiento de pago en el domicilio real o procesal del denunciado. La Primera Ponencia sostenía que la notificación debe efectuarse en el domicilio real, no siendo necesaria la notificación en el domicilio procesal. La Segunda Ponencia, por el contrario, establecía que la resolución de requerimiento de pago basta que se notifique al domicilio procesal; siendo el fundamento de esta ponencia que el proceso por el delito de Omisión a la Asistencia Familiar ha nacido de un proceso civil en el que se ha respetado el debido proceso; por lo que, el emplazamiento deberá efectuarse en el domicilio procesal señalado en el proceso de alimentos. El Pleno por unanimidad adoptó la segunda ponencia: La resolución de requerimiento de pago basta que se notifique al domicilio procesal, a excepción del caso de rebeldía que deberá efectuarse en el domicilio declarado en RENIEC.

Ahora bien, recientemente en Pleno Jurisdiccional Distrital de Familia de la Corte Superior de Justicia de Lima Este, ante la pregunta planteada: ¿Es necesario que el requerimiento de pago por el monto aprobado de las pensiones devengadas de alimentos sea dirigido al domicilio real del demandado que tiene registrado en su Ficha RENIEC o es suficiente que se le notifique con dicho requerimiento a su domicilio procesal o casilla electrónica? Los jueces por mayoría se decantaron, erróneamente desde mi humilde opinión ${ }^{11}$, por la segunda ponencia que establecía: Sí es necesario que la resolución de requerimiento de pago de las pensiones devengadas sea notificada al domicilio real del demandado señalado en su Ficha RENIEC; siendo insuficiente la notificación al domicilio procesal o casilla electrónica.

En conclusión, podemos sostener que si bien existen plenos jurisdiccionales contradictorios, nos inclinamos por los criterios adoptados

11 En este Pleno Jurisdiccional el autor se encontraba a favor de la primera ponencia; sosteniendo como razones que se debe priorizar la efectividad de la sentencia y el pago de la deuda alimentaria; y ya habiendo domicilio del demandado fijado en el proceso de alimentos, aquél tiene pleno conocimiento de las resoluciones expedidas, incluso en su fase de ejecución; por lo que, es innecesario notificar al domicilio real cuando ha señalado su domicilio procesal o casilla electrónica. Sin embargo, por una mayoría de 08 a 06, se estableció la segunda ponencia. 
por los jueces que establecieron como criterios la notificación al domicilio procesal o casilla electrónica del Abogado del obligado, salvo cuando se encuentre en calidad de rebeldía, en cuyo caso corresponde notificar al domicilio real que figura en la Ficha RENIEC. Todas las notificaciones, también la del requerimiento de pago de las pensiones devengadas, dirigidas al domicilio procesal o casilla electrónica resultan plenamente válidas; desconocer la validez y los efectos de dichas notificaciones implica invalidar las notificaciones efectuadas en el proceso de alimentos para la determinación de la deuda alimentaria; situación que contraviene el derecho a la efectividad de tutela judicial, conforme a los criterios establecidos por la Corte Interamericana de Derechos Humanos en el caso Furlan y Familiares vs Argentina.

Ante estas incongruencias en la actuación de los órganos de la administración de justicia, se hace necesario que se fijen reglas idóneas y eficaces que permitan una efectiva ejecución de las sentencias alimentarias.

\section{DESCONOCE LOS CRITERIOS ASUMIDOS POR EL TRIBUNAL CONSTITUCIONAL}

En sede de fiscalía penal se considera que no basta que la resolución que aprueba las pensiones devengadas y requiere su pago se encuentre notificado al domicilio procesal o a la casilla electrónica del Abogado del demandado, sino que es indispensable que la notificación se dirija al domicilio real (que figura en la Ficha RENIEC del demandado); caso contrario, no existe certeza que el demandado ha tomado conocimiento del requerimiento y por tanto no se podría iniciar la acción penal por el delito de omisión a la asistencia familiar.

Sin embargo, consideramos que la exigencia de notificar al domicilio real del demandado no se encuentra prevista en ninguna norma jurídica que la ampare; de manera que, resulta suficiente y conforme a las normas vigentes la notificación de la resolución de requerimiento de pago de las pensiones devengadas al domicilio procesal o a las casillas electrónicas señaladas en el proceso de alimentos. El Tribunal Constitucional, en el Exp. N ${ }^{\circ}$ 01283-2012PA/TC ha establecido lo siguiente:

... se observa, respecto de la resolución cuestionada, que en el proceso de alimentos se ha realizado la notificación de acuerdo con el domicilio procesal que el recurrente indicó en su escrito de contestación de la demanda, y no se evidencia que haya manifestado variación alguna. ... siendo así, las alegaciones vertidas por el recurrente respecto a 
que no tomó conocimiento oportuno de la resolución que contenía la liquidación de pensiones devengadas resultan desvirtuadas ... toda vez que al estar válidamente notificado, el actor tenía expedito su derecho a interponer el medio impugnatorio pertinente. (Resaltado agregado)

En el proceso de amparo recaído en el Exp. 00848-2009-PA/TC, se cuestionaba que nunca se notificó ninguna resolución dictada en el proceso de alimentos al demandado, lo que no garantizó su legítimo derecho de defensa y a ser oído antes que se emita resolución. Sobre el particular, en la sentencia constitucional se estableció que:

... de las mismas piezas procesales que corren de fojas 62, 63 y 65, y del reporte de seguimiento de expedientes que corre a fojas 88, 87 y 86, se aprecia que el Juzgado cumplió con notificar al recurrente la resolución № 1 que dispone remitir los actuados al Ministerio Público, la resolución $\mathrm{N}^{\mathrm{o}} 2$ que tiene por recibido el dictamen y señala vista de la causa para el día 4 de febrero del 2005, la resolución N. 3 que concede el uso de la palabra a la demandante y obviamente la sentencia que declara fundada la demanda, todas ellas remitidas a la Casilla No 322 del Cono Norte, domicilio legal designado por el accionante, cuyos cargos se encuentran debidamente recepcionados conforme se ha podido comprobar del reporte de expedientes del Poder Judicial que vía web es de público conocimiento. (Resaltado agregado)

Existe reiterada jurisprudencia del Tribunal Constitucional que valida las notificaciones a los domicilios procesales, a las casillas físicas y, desde el 2014, a las casillas electrónicas señaladas por las partes en el proceso de alimentos, en virtud al artículo 155-E del Texto Único Ordenado de la Ley orgánica del Poder Judicial, incorporado por la Primera Disposición Complementaria Modificatoria de la Ley $\mathrm{N}^{\circ}$ 30229. De esta forma, consideramos que la exigencia de notificar la resolución que aprueba las pensiones devengadas y dispone el requerimiento de pago al domicilio real de los demandados, contraviene la propia y reiterada doctrina jurisprudencial del Tribunal Constitucional.

\subsection{EL IMPEDIMENTO DE DECRETAR EL APERCIBIMIENTO DE OFICIO PARA REMITIR COPIAS CERTIFICADAS DE LAS PENSIONES DEVENGADAS AL MINISTERIO PÚBLICO}

Se ha convertido en práctica judicial reiterada que el impulso de los procesos judiciales siempre corre a cargo de las partes; son las partes quienes 
deben señalar expresamente el acto procesal que corresponde expedir al órgano jurisdiccional. Los procesos de alimentos no son ajenos a esa equivocada práctica realizada por los juzgados que conocen dichos procesos; de manera que, se sigue pensando que toda actuación procesal dependerá necesariamente de lo que las partes hayan formulado expresamente en sus escritos.

En etapa de ejecución de la sentencia de alimentos, una vez aprobada la liquidación de las pensiones devengadas y de los intereses legales, se requiere al obligado el pago de la deuda aprobada. En esta circunstancia del proceso, surge la pregunta si el juez podría decretar de oficio el apercibimiento contenido en el artículo 566-A del CPC; esto es, remitir copia certificada de la liquidación de las pensiones devengadas y de las resoluciones respectivas al Ministerio Público para el inicio de la denuncia penal por el delito de Omisión a la Asistencia Familiar.

Se sostiene que el juez no podría decretar de oficio dicho apercibimiento; toda vez que, la propia norma dispone que “... el Juez, a pedido de parte y previo requerimiento a la parte demandada bajo apercibimiento expreso, remitirá copia certificada de la liquidación de las pensiones devengadas y de las resoluciones respectivas al Fiscal Provincial de Turno ...". De esta forma, se viene interpretando en el sentido de que debe ser la parte quien precise que ante el incumplimiento de la deuda aprobada se remita copia certificada al Ministerio Público:

... Aprobar la Liquidación de Pensiones Alimenticias Devengadas ... REQUIÉRASE al demandado ... cumpla con hacer efectivo su pago; bajo apercibimiento de ley en caso de incumplimiento; por lo cual la demandante deberá cumplir con precisar si el requerimiento de pago de lo adeudado se va a efectuar bajo el apercibimiento señalado en el artículo 566-A del CPC, o de inicio de ejecución forzada a efectos de continuar con la secuela de proceso. (Resaltado agregado)

Dicho criterio también fue asumido en el Pleno Jurisdiccional Distrital de Familia, realizado en la Corte Superior de Justicia de Lima Este, el 23 de noviembre de 2018, con la siguiente formulación del problema: ¿El apercibimiento de remitir copias certificadas de las pensiones devengadas de alimentos al Fiscal Provincial Penal de Turno, para el inicio la acción penal por el delito de Omisión a la Asistencia Familiar, debe ser solicitado necesariamente por la parte demandante o puede ser decretado de oficio por el Juez? 
Las juezas y jueces que participaron en el pleno consideraron que el apercibimiento de remitir copias certificadas al Ministerio Público ante el incumplimiento de pago del obligado solo podía ser a pedido de parte; no puede el juez decretarlo de oficio; de manera que por mayoría se adoptó la ponencia siguiente: "El apercibimiento de remitir copias certificadas de las pensiones devengadas de alimentos al Fiscal Provincial Penal de Turno para la denuncia penal por el delito de la Omisión a la Asistencia Familiar, debe ser solo a pedido de parte. El juez no puede decretar de oficio dicho apercibimiento" ${ }^{\prime 12}$

Al respecto, somos de la opinión que la norma no prohíbe expresamente decretar de oficio el apercibimiento de remitir copias al Ministerio Público para la formulación de la denuncia penal. Sin embargo, genera incertidumbres en su interpretación y aplicación al prescribir que el juez, a pedido de parte, remitirá copia certificada de la liquidación de las pensiones devengadas; lo que ha motivado que jueces y juezas exijan que la propia parte precise qué apercibimiento se va imponer al obligado en caso este no cumpla con el pago de la deuda alimentaria, como se ha anotado líneas arriba.

Exigir que la parte impulse la ejecución de la sentencia de alimentos contraviene lo establecido por la Corte Interamericana de Derechos humanos en el caso Furlan y Familiares vs. Argentina, pues todas las autoridades públicas, dentro del marco de su competencia, deben atender las decisiones judiciales, así como dar impulso y ejecución de las mismas sin obstaculizar el sentido y alcance de la decisión ni retrasar indebidamente su ejecución. Sin perjuicio de ello, consideramos que el legislador debería proveer a la judicatura de reglas idóneas y no ambiguas o contradictorias para la efectiva y pronta ejecución de las sentencias alimentarias.

\section{ALGUNAS CONCLUSIONES}

La pensión de alimentos es un auténtico derecho fundamental reconocido por el ordenamiento interno y como derecho humano por el ordenamiento internacional; de manera que, su goce y satisfacción efectiva deberían estar plenamente garantizados por los mecanismos de tutela de derechos que establece el Estado; esto es, a través del proceso de alimentos. Sin embargo, se ha advertido que el referido proceso judicial viene presentando

12 Como magistrado que también participó en dicho pleno jurisdiccional, consideré que no existe norma expresa que prohíba al juez remitir de oficio las copias de la liquidación de devengados al Ministerio Público; y es en base a la efectividad de las resoluciones judiciales, que el juez pueda adoptar todas las medidas de ejecución posible para que se cumpla la sentencia, en forma verdadera y oportuna, siempre garantizado el derecho al contradictorio del obligado. 
serios inconvenientes, sobre todo, en la fase de ejecución de la sentencia de la pensión de alimentos.

La falta de reglas idóneas y la aplicación formal de las que prevé nuestro ordenamiento procesal vienen generando demoras excesivas en la ejecución de las sentencias alimentarias, tal como lo ha advertido el Informe de Adjuntía Nº01-2018-DP/AAC, de la Defensoría del Pueblo; pese a ello, no existe un enfoque legislativo real respecto de la crisis en los procesos de alimentos; se sigue pensando que el problema solo está en el acceso y el trámite. Sin embargo, -como se ha indicado- el verdadero problema de los procesos de alimentos se encuentra en la etapa de ejecución de sentencia.

De esta forma, no se garantiza el derecho a la tutela judicial efectiva, pues de nada sirve que el juzgado emita sentencia en el breve plazo si luego, en base a formalismos exagerados y a la omisión legislativa de reglas idóneas, la ejecución puede extenderse en el tiempo de manera irrazonable $\mathrm{o}$, incluso, la sentencia puede quedar incumplida. Por consiguiente, debería reformarse las reglas de ejecución vigentes; toda vez que, como actualmente se encuentran diseñadas, no garantiza de manera efectiva y oportuna contar con las pensiones alimenticias declaradas judicialmente.

Las reglas de ejecución de las sentencias alimentarias es uno de los temas que poco interés ha tenido por parte del legislador y de los juristas, así como de las propias autoridades del Poder Judicial; sin embargo, es quizá uno de los factores problemáticos -no el único por supuesto- que viene generando una excesiva carga procesal en materia de alimentos ante los órganos jurisdiccionales de su competencia.

\section{REFERENCIAS}

Aguilar Llanos, Benjamín (2016). Tratado de Derecho de Familia. Lima: Lex \& Iuris.

Bachof, Otto (1985.) Jueces y Constitución. Madrid: Editorial Civitas.

Chamorro Bernal, Francisco (1994). La tutela judicial efectiva. Derechos y garantías procesales derivados del artículo 24.1 de la Constitución. Barcelona: Bosch

Espinoza Saldaña, Eloy (2020). Sobre los límites del juez constitucional. Segunda Edición. Lima: Zela

Fioravanti, Mauricio (2009). L Los Derechos Fundamentales. Apuntes de Historia de las Constituciones. Sexta edición. Madrid: Trotta. 
Gonzales Pérez, Jesús (1980). Derecho Procesal Constitucional. Madrid: Civitas.

Guastini, Riccardo (2018). Interpretar y Argumentar. Lima: Legales.

Haberle, Pedro (1991). La Garantía Constitucional de los Derechos Fundamentales. Madrid: Civitas.

Marinoni, Luiz Guilherme (2016). Tutela anticipatoria y tutela inhibitoria. Lima: Palestra.

Landa Arrollo, Cesar (2017). La Constitucionalización del Derecho. El caso del Perú. Lima: Palestra.

Priori Posada, Giovanni (2020). La Constitucionalización del Derecho Procesal. Consulta: 15 de septiembre de 2020. https://www.academia. edu/11549445/La_constitucionalizaci\%C3\%B3n_del_derecho_ procesal

Sáenz, Dávalos, Luis (2009). Los derechos no enumerados y sus elementos de concretización". Derechos constitucionales no escritos reconocidos por el Tribunal Constitucional. Gaceta; $13-47$.

Sarlet, Ingo W. (2019.) La eficacia de los derechos fundamentales. Una teoría general desde la perspectiva constitucional. Lima: Palestra.

Ramirez Huaroto, Beatriz (2018). Derecho de acceso a la justicia en clave de género: implicancias del componente de buena calidad en casos de violencia contra las mujeres". Derechos Fundamentales. Actas de las III Jornadas Nacionales de Derechos Fundamentales. Lima: Palestra; 321 - 344.

Ródenas, Ángeles (2012). Los intersticios del Derecho. Barcelona: Marcial Pons. Consulta: 22 de septiembre de 2020 https://www.marcialpons.es/ media/pdf/9788497689601.pdf

Trazegnies Granda, Fernando. La muerte del legislador. Consulta: 06 de septiembre de 2020. https:/ / docs.google.com/

Zagrebelsky, Gustavo (1999). El derecho dúctil. La ley, derechos y justicia. Segundo Edición. Madrid: Trotta.

Fecha de recepción: 18-09-2020

Fecha de aceptación: 